\title{
Social Isolation Following Embryo Transfer increases Success Rates in IVF and ICSI Cycles
}

\author{
Kamini A Rao, Muthugadhahalli S Srinivas, Anu Kottur, Partha P Majumdar, Pushpa M Bhargava
}

\begin{abstract}
Background and objective: Bruce et al had shown, during 1959 to 1968, that if, 24 hours after mating, a mouse belonging to a different inbred strain than the stud mouse was placed in the cage of the female mouse, partitioned in such a way that no physical contact of the nonstud male with the female was possible, pregnancy was blocked. We, therefore, decided to determine whether, by analogy with mice, isolation of women from all other men except the husband, for 3 days after embryo transfer following in vitro fertilization (IVF) or intracycloplasmic sperm injection (ICSI), increases the establishment of pregnancy.
\end{abstract}

Method: We isolated randomly selected 729 women from all other men except the husband for 3 full days after embryo transfer following IVF/ICSI, and followed them to the end of pregnancy; 1005 randomly selected women who were treated similarly but not isolated served as the control group.

Results: The establishment of clinical pregnancy as well as live births were more than $50 \%$ higher in the isolated group than in the control.

Conclusion: The social isolation as mentioned above could substantially increase the success rates in IVF or ICSI. While the exact mechanism of this phenomenon is yet to be understood, one possible explanation may be, by analogy with mice, an olfactory block to implantation.

Keywords: ICSI, IVF, Social isolation.

How to cite this article: Rao KA, Srinivas MS, Kottur A, Majumdar PP, Bhargava PM. Social Isolation Following Embryo Transfer Increases Success Rates in IVF and ICSI Cycles. Int J Infertility Fetal Med 2012;3(1):8-14.

\section{Source of support: Nil}

Conflict of interest: There is no conflict of interest for any of the authors.

\section{INTRODUCTION}

The success rate of clinical pregnancy in women after in vitro fertilization (IVF) or intracytoplasmic sperm injection (ICSI) in the first three attempts, with two to three embryos transferred, has been reported to range from 25 to $33 \% .^{1-3}$ Further, this success rate seems to be identical with that obtained in women in natural cycles, when the couple does not suffer from any known form of infertility and the intercourse takes place at the right time. ${ }^{4-6}$ While seeking

Date of Received: 27-12-11

Date of Acceptance: 30-12-11

Date of Publication: January 2012 an explanation of the above phenomenon, we recalled the observation of Bruce, followed by others, during 1959 to 1968, that if, 24 hours after mating, a mouse belonging to a different inbred strain than the stud mouse was placed in the cage of the female mouse, partitioned in such a way that no physical contact of the non-stud male with the female was possible, pregnancy was blocked. ${ }^{7-12}$ It, therefore, seemed possible that the above-mentioned low percentage of successful pregnancies in the human species, may be due to the exposure of the woman, after IVF, ICSI or sexual intercourse, without physical contact, to men other than the male partner. We, therefore, decided to investigate the effect of isolating the woman after IVF or ICSI for 3 days that are required for implantation, on establishment of clinical pregnancy.

\section{MATERIALS AND METHODS}

\section{IVF, ICSI, Isolation and Determination of Clinical Pregnancy}

Ovarian stimulation for the release of oocytes was done using a GnRH agonist ${ }^{13}$ in $95 \%$ of both the control and the isolated groups defined later; in the remaining $5 \%$ of the cases in both the groups a GnRH antagonist was used. ${ }^{14}$

A recent meta-analysis has shown that the probability of clinical pregnancy after ovarian stimulation is independent of the type of analog used. ${ }^{15}$ Oocyte retrieval, IVF and ICSI were performed as per standard procedures. One to four of day-three embryos obtained after ovarian stimulation, oocyte collection and IVF or ICSI were transferred into the woman. Clinical pregnancy was assessed 20 to 25 days after embryo transfer, by fetal heart beat as determined by ultrasonography, each heart corresponding to a fetus in a sac. In this study, in no case there was more than one fetus in a sac. As the maximum number of embryos transferred was four, the maximum number of sacs (i.e. fetuses) in a woman was also four. The number of sacs, which was noted, would thus determine if she may give birth to a singleton, twin, triplet or quadruplet.

During 2003 to 2006, isolation of the women after embryo transfer was done at the institution where this study was performed. This group is referred to as the isolated group. Inclusion in this group depended entirely on availability of beds in the institution, which was a 
random phenomenon. Every woman who was offered a bed and isolation, agreed and provided informed consent. Therefore, there was no selection bias. Isolation was done for three full days (days, 2, 3 and 4 after embryo transfer) with no cost to the woman; during this period, the woman did not see any other man except the husband. In other words, while the woman was in the hospital room (each woman had a separate room $(12 \times 10 \mathrm{ft})$ with an attached toilet and airconditioning which provided a positive pressure in the room), no man except the husband was permitted in the room. The door of the room was kept closed and opened only to provide the usual service for which only women were used. All women who could not be isolated on account of lack of a room in the institution served as the control and are referred to as the control group. There was thus no identifiable selection bias in recruitment of women in the control group.

During 2007 and 2008, isolation was done at the woman's home to determine if the hospital environment could be a factor influencing any difference between the success rates of the isolated and the control group. All reporting couples during these 2 years were asked, if the wife would be able to isolate herself at home (that is, to stay at home and not move out for three full days after embryo transfer, and not allow any man other than her husband to enter her home for the three days) as was done in the hospital. All of those living alone with the husband agreed and were assigned to the isolated group. An informed consent was also taken. Those who were a part of a joint family could not satisfy the condition of isolation; every second or third woman among them, selected randomly, was included in the control group. Therefore, there was no identifiable selection bias also in the case of women recruited in the control group during 2007 and 2008.

No woman enrolled in this study smoked. No smoking was permitted in the hospital room; in fact, the entire hospital is a no-smoking area. There was no restriction on any physical movement or activity in the case of women who were isolated, whether at home or in the hospital. The attempt in this study was to come as close as was possible to real-life situations.

\section{Description of the Isolated and Control Groups}

This study was conducted on 1,734 married couples requiring IVF or ICSI between 2003 and 2008, out of which 729 belonged to the isolated group and the remaining 1005 to the control group. As the number of women in the control $(>1000)$ and the isolated (>700) was very large, sample size calculation had little meaning. With the above sample sizes, to detect a difference in proportion $=0.05$, at a $5 \%$ level of significance, the statistical power will be between
98 and $100 \%$. As this was not a matched case-control study (which was, logistically, virtually impossible), the numbers in the control and isolated groups did not have to be identical; again, as they were both very large, this difference would not vitiate our results.

In the control and the isolated groups, 216 and 84 women respectively, had earlier undergone one IVF/ICSI cycle without isolation, that did not lead to pregnancy. For the remaining (789 in the control group and 645 in the isolated group), it was their first IVF/ICSI attempt. All the 729 women in the isolated group were isolated for the first time. In every case, the age of the woman, the nature of infertility (primary or secondary) and the cause of infertility in the woman and the man (in the latter case, to determine whether IVF or ICSI should be performed) were noted.

Some women ( 31.0 and $32.5 \%$ in the control and isolated groups respectively) had a pregnancy before they came to the clinic, but were unable to conceive again, unlike the rest $(69.0$ and $67.5 \%$ in the control and isolated group respectively) who had not been able to conceive earlier. The nature of infertility in the former is referred to as secondary and in the latter, primary. The causes of infertility in women were ovarian, tubal, endometriosis, or unexplained $(21.9,42.3,14.2$ and $21.6 \%$ respectively, in the control group; and 22.6, 43.5, 13.6 and 20.3\% respectively, in the isolated group); and in men, teratospermia, oligospermia, asthenospermia or oligoasthenospermia $(2.8,19.8,13.1$ and $13.7 \%$ respectively, in the control group, and 5.0, 21.5, 13.6 and $13.4 \%$ respectively, in the isolated group, the remaining $50.6 \%$ in the control group and $46.5 \%$ in the isolated group being normospermic).

Statistical analysis: Tests of independence in contingency tables, including tests of equality of two proportions, were done using Chi-square tests. Tests of equality of mean values were performed using t-tests. Effects of covariates on the binary variable (success or failure of clinical pregnancy) were tested using a logistic regression model. All statistical calculations were performed using the SPSS package.

\section{RESULTS}

\section{Effect of Isolation on First and Second IVF/ICSI Attempt}

Out of the 1,005 women in the control group, 216 went through two IVF/ICSI cycles, in none of which the women were isolated; the results of both the cycles were recorded. Out of 729 women in the isolated group, 84 went through two cycles; they were not isolated in the first cycle but isolated only in the second cycle. Therefore, all the 729 women in the isolated group went through only one cycle of isolation. 
Table 1 gives the number of clinical pregnancies obtained in each of the two groups (control and isolated), year-wise from 2003 to 2008 as well as the total for all the years combined. For women in the control group, it was their first attempt of IVF/ICSI; for women in the isolated group, it was the first time that the woman was isolated after IVF/ICSI even though she may have gone through an unsuccessful IVF/ICSI cycle earlier. Table 1 shows that the clinical pregnancy rate in the isolated group was over $50 \%$ higher than in the control group for all the years taken together $(p<0.0001)$. Further, in every year of treatment there was a higher proportion of success among the isolated women than among the control women. However, the proportion of success was not significantly higher in the year $2004(p=0.236)$ but was significantly higher in all the other years $(\mathrm{p}<0.05)$. Fluctuation in the rate of pregnancy during routine work in an assisted reproductive technology unit is known. ${ }^{16}$ Isolation at home was as effective as isolation in the hospital, which showed that confinement to one room in the hospital was not responsible for the striking difference between the isolated and the control groups in respect of the success rates.

Table 2 gives the rates of establishment of clinical pregnancy in the second IVF/ICSI attempt, when the woman was not isolated in either attempt (the control group) and when she was isolated in the second attempt and not in the first (the isolated group). Here again, the success rate in the isolated group was more than $50 \%$ higher than in the control group $(\mathrm{p}<0.0001)$.
Even if we exclude from the experimental group in Table 1, the 84 cases (Table 2) where there was failure in the first attempt and isolation in the second (in which case, there were 41 clinical pregnancies), the conclusion from the data of Table 1 will remain the same (for, out of 729 minus 84, that is, 645 women in the experimental group, pregnancy would then have been established in 325 minus 41, that is, in 284 cases, giving a success rate of $44.03 \%$ which is not significantly different from the success rate of $44.58 \%$ mentioned for the total in Table 1).

The ratio of live births to clinical pregnancy was 0.850 in the isolated group and 0.852 in the control group; the difference was statistically not significant.

Isolation of the woman from men other than the partner, for 3 days after IVF or ICSI and subsequent embryo transfer, therefore, appears to lead to a remarkable (over 50\%)

\begin{tabular}{|c|c|c|}
\hline $\begin{array}{l}\text { Pregnancy in } \\
\text { second attempt }\end{array}$ & Control group & Isolated group \\
\hline Successful & 69 (31.94) & $41(48.81)$ \\
\hline Unsuccessful & 147 (68.06) & 43 (51.19) \\
\hline Total & $216(100.00)$ & $84(100.00)$ \\
\hline
\end{tabular}

Figures in parentheses indicate percentages. In the control group, the women were not isolated in either attempt; in the isolated group, the women were isolated in the second attempt but not in the first. Successful pregnancies in this table are not included in Table 1 for the control group, but included in Table 1 for the isolated group as it was the first isolation cycle for all in this group, irrespective of whether or not the woman had gone through another cycle earlier

Table 1: Clinical pregnancy in first IVF/ICSI attempt among control and isolated women

\begin{tabular}{|c|c|c|c|c|c|}
\hline Year of recruitment & Group & Total & No (\%) successful & Chi-square & $p$-value \\
\hline 2003 & $\begin{array}{l}\text { Control } \\
\text { Isolated } \\
\text { Total }\end{array}$ & $\begin{array}{r}160 \\
98 \\
258\end{array}$ & $\begin{array}{l}46(28.75) \\
40(40.82) \\
86(33.33)\end{array}$ & 3.982 & 0.046 \\
\hline 2004 & $\begin{array}{l}\text { Control } \\
\text { Isolated } \\
\text { Total }\end{array}$ & $\begin{array}{l}200 \\
109 \\
309\end{array}$ & $\begin{array}{l}55(27.50) \\
37(33.94) \\
92(29.77)\end{array}$ & 1.402 & 0.236 \\
\hline 2005 & $\begin{array}{l}\text { Control } \\
\text { Isolated } \\
\text { Total }\end{array}$ & $\begin{array}{l}172 \\
127 \\
299\end{array}$ & $\begin{array}{r}57(33.14) \\
63(49.61) \\
119(39.80)\end{array}$ & 7.496 & 0.006 \\
\hline 2006 & $\begin{array}{l}\text { Control } \\
\text { Isolated } \\
\text { Total }\end{array}$ & $\begin{array}{l}238 \\
265 \\
503\end{array}$ & $\begin{array}{r}78(32.77) \\
124(46.79) \\
202(40.16)\end{array}$ & 10.255 & 0.001 \\
\hline 2007 & $\begin{array}{l}\text { Control } \\
\text { Isolated } \\
\text { Total }\end{array}$ & $\begin{array}{r}110 \\
57 \\
167\end{array}$ & $\begin{array}{l}29(26.36) \\
28(49.12) \\
56(33.53)\end{array}$ & 7.432 & 0.006 \\
\hline 2008 & $\begin{array}{l}\text { Control } \\
\text { Isolated } \\
\text { Total }\end{array}$ & $\begin{array}{r}125 \\
73 \\
198\end{array}$ & $\begin{array}{l}29(23.20) \\
33(45.21) \\
62(31.31)\end{array}$ & 10.376 & 0.001 \\
\hline Total & $\begin{array}{l}\text { Control } \\
\text { Isolated } \\
\text { Total }\end{array}$ & $\begin{array}{r}1,005 \\
729 \\
1,734\end{array}$ & $\begin{array}{l}294(29.25) \\
325(44.58) \\
619(35.69)\end{array}$ & 41.77 & $<0.0006$ \\
\hline
\end{tabular}


enhancement in success rates, as measured by clinical pregnancy, in the first and second cycles. The success rates of clinical pregnancy in the control group in the first two attempts (Tables 1 and 2) fell within the range (25-33\%) reported earlier. ${ }^{1-3}$

\section{The Constraints}

The success of ART depends upon several factors, namely the age of the woman, the method of stimulation used, the nature and cause of infertility, the number and quality of the embryos transferred and the receptivity of the endometrium. It was, therefore, important to ensure that these factors did not confound the significant difference we observed in the IVF/ICSI success rates in the control $(n=1005)$ and the isolated $(n=729)$ groups.

As is mentioned in materials and methods, the methods of stimulation used in the two groups were identical. The percentage of women with primary infertility in the control and isolated groups was similar: 69.0 and 67.5 respectively (Chi-square $=0.419$, df $=1, p=0.517)$. As has been mentioned under materials and methods, the percentage distribution of women with different types of infertility (ovarian, tubal, endometriosis or unexplained) in the two groups was also similar, as was the case with the percentage distribution of men with different types of infertility (teratospermia, oligospermia, asthenospermia or oligoasthenospermia) or those who were normospermic. The average number of oocytes retrieved, too, was about the same in the control and the isolated groups: 9.7 and 9.2 respectively. Only grade A or B embryos were used in this study. Endometrial thickness in both the groups was between 7 and $12 \mathrm{~mm}$. These factors are, therefore, extremely unlikely to vitiate the results we have reported in regard to the difference in establishment of clinical pregnancy between the control and the isolated groups.

In Table 3, we show that while variables (covariates), such as the age of the woman and the number of embryos transferred into her after IVF/ICSI, played a role (as is wellknown) in successful establishment of clinical pregnancy within each group (control or isolated), the nature and the cause of infertility had no such effect in either group.

Table 4 shows that the percentage distribution of number of embryos transferred, was similar in the control and the isolated groups. The mean ages of the women in the control and the isolated groups were also similar: $33.96 \pm 0.158$ and $33.50 \pm 0.170$ respectively. However, the percentage distribution of different age classes in the control and the isolated group was significantly different (Table 5). We, therefore, compared the successful establishment of pregnancy as well as the number of embryos transferred in women of different age classes in the control and the isolated groups (Table 5).

Table 5 shows that within each age class, the number of embryos transferred into the control and the isolated women was similar and the difference was not statistically significant.

\begin{tabular}{|c|c|c|c|c|c|}
\hline \multirow[t]{2}{*}{ Group } & \multirow[t]{2}{*}{$N$} & \multicolumn{4}{|c|}{ Covariate } \\
\hline & & Age (years) & $\begin{array}{l}\text { No. of embryos } \\
\text { transferred }\end{array}$ & $\begin{array}{l}\text { Nature of infertility } \\
\text { in female }\end{array}$ & $\begin{array}{c}\text { Cause of infertility } \\
\text { in female }\end{array}$ \\
\hline Control & 989 & $\begin{array}{c}<0.001 \\
(33.90 \pm 0.159)\end{array}$ & $\begin{array}{c}0.030 \\
(2.90 \pm 0.026)\end{array}$ & 0.064 & 0.438 \\
\hline Isolated & 728 & $\begin{array}{c}<0.0006 \\
(33.50 \pm 0.171)\end{array}$ & $\begin{array}{c}0.018 \\
(2.91 \pm 0.030)\end{array}$ & 0.755 & 0.360 \\
\hline
\end{tabular}

Figures in parentheses are values of mean \pm SEM among women in whom pregnancy was established. The difference between the mean ages of control and isolated women, and that between the mean number of embryos transferred into them, was statistically not significant ( $p=0.085$ and 0.666 respectively). Data on number of embryos transferred were missing for 17 women (16 controls and 1 isolated) who have been, therefore, excluded

Table 4: Number of embryos transferred and multiple pregnancies in the control and the isolated groups

\begin{tabular}{|c|c|c|c|c|c|c|c|c|}
\hline \multirow[t]{3}{*}{$\begin{array}{c}\text { Number of } \\
\text { embryos transferred }\end{array}$} & \multicolumn{2}{|c|}{$\begin{array}{l}\% \text { of women in } \\
\text { the group }\end{array}$} & \multicolumn{6}{|c|}{$\begin{array}{c}\% \text { of women with multiple } \\
\qquad(\geq 2) \text { sacs }\end{array}$} \\
\hline & \multirow[t]{2}{*}{ Control } & \multirow[t]{2}{*}{ Isolated } & \multicolumn{3}{|c|}{ Control group } & \multicolumn{3}{|c|}{ Isolated group } \\
\hline & & & 2 sacs (\%) & 3 sacs (\%) & 4 sacs (\%) & 2 sacs (\%) & 3 sacs (\%) & $4 \operatorname{sacs}(\%)$ \\
\hline 1 & 4.47 & 4.15 & X & X & $x$ & $x$ & $x$ & $x$ \\
\hline 2 & 24.26 & 24.07 & 2.83 & $x$ & $x$ & 3.43 & $x$ & $\mathrm{X}$ \\
\hline 3 & 49.14 & 49.38 & 5.16 & 1.11 & $x$ & 7.97 & 2.34 & $x$ \\
\hline 4 & 22.13 & 22.40 & 2.93 & 2.33 & 0.30 & 3.43 & 1.79 & 0.30 \\
\hline
\end{tabular}

The number in the control and the isolated groups, of which percentages are given, were 989 and 728 respectively, data for the number of embryos transferred not being available for 16 women in the control and one woman in the isolated group, $X=$ not relevant 
However, in spite of an equal number of embryos having been transferred into women of both the groups, the proportion of women in whom pregnancy was successfully established (in the first cycle; Table 1) was higher among isolated women than among control women in all ageclasses, although the difference was not statistically significant in women above 40 years of age. Results of a similar analysis done for the second cycle are shown in Table 6; on account of the number being small, two age groups were combined for the analysis, the results of which were similar to that obtained for the first cycle in Table 5.

It is noteworthy that the number of sacs obtained per embryo transferred in 728 women in the isolated group $(0.250 \pm 0.012)$ was significantly larger than the same number $(0.198 \pm 0.010)$ for 989 women in the control group $(\mathrm{t}=-310, \mathrm{df}=1,715, \mathrm{p}=0.001)$, while there was no significant difference between the two groups in regard to clinical pregnancy per embryo transferred (isolated group, 0.3340 ; control group, $0.3324 ; \mathrm{p}=0.884$ ), or number of sacs per clinical pregnancy (isolated group, 1.5753; control group, 1.5232; $\mathrm{p}=0.520$ ). Table 4 also shows that the incidence of multiple pregnancies was higher in the isolated group in comparison to the control, irrespective of the number of embryos transferred (2, 3 or 4$)$.

\section{DISCUSSION}

From what is said in the preceding section, it would appear most likely that, under the conditions of the experiment over 6 years, there was no significant difference between the control group and the isolated group in regard to any other conceivable factor affecting fertility than the social isolation of the woman for 3 days after IVF/ICSI and embryos transfer. Our observations, therefore, provide strong evidence in favor of the view that such isolation increases the rate of successful clinical pregnancy (and live birth) by over $50 \%$.

By analogy with the work done on mice, ${ }^{7-12}$ and as pheromones are known to regulate a large number of behavioral patterns in the animal world ${ }^{9,12,17,18}$ —including humans where, e.g., the menstrual cycles of women living

\begin{tabular}{|c|c|c|c|c|c|c|c|}
\hline \multirow{2}{*}{$\begin{array}{l}\text { Age-class } \\
\text { (years) }\end{array}$} & \multirow[t]{2}{*}{ Groups } & \multicolumn{3}{|c|}{ Age } & \multicolumn{3}{|c|}{ No. of embryos transferred } \\
\hline & & $N$ & $\begin{array}{l}\text { Number (\%) of } \\
\text { successful clinical } \\
\text { pregnancies }\end{array}$ & $\begin{array}{c}\text { p-value of } \\
\text { difference } \\
\text { between control } \\
\text { and isolated } \\
\text { women }\end{array}$ & $N$ & Mean \pm SEM & $\begin{array}{c}p \text {-value of } \\
\text { difference } \\
\text { between control } \\
\text { and isolated } \\
\text { women }\end{array}$ \\
\hline \multirow[t]{2}{*}{$\leq 29$} & Control & 203 & $67(33.0)$ & & 203 & $2.87 \pm 0.060$ & \\
\hline & Isolated & 164 & $90(54.9)$ & $<0.0006$ & 164 & $2.96 \pm 0.061$ & 0.297 \\
\hline \multirow[t]{2}{*}{$30-32$} & Control & 237 & $81(34.2)$ & & 235 & $2.84 \pm 0.052$ & \\
\hline & Isolated & 156 & $78(50.0)$ & 0.002 & 156 & $2.90 \pm 0.062$ & 0.615 \\
\hline \multirow[t]{2}{*}{$33-35$} & Control & 176 & $49(27.8)$ & & 171 & $2.81 \pm 0.064$ & \\
\hline & Isolated & 115 & $50(43.5)$ & 0.008 & 114 & $2.84 \pm 0.073$ & 0.574 \\
\hline \multirow[t]{2}{*}{$36-40$} & Control & 259 & $76(29.3)$ & & 255 & $2.89 \pm 0.047$ & \\
\hline & Isolated & 245 & $95(38.8)$ & 0.030 & 245 & $2.94 \pm 0.052$ & 0.419 \\
\hline \multirow[t]{2}{*}{$>40$} & Control & 130 & $21(16.2)$ & & 125 & $3.00 \pm 0.070$ & \\
\hline & Isolated & 49 & $12(24.5)$ & 0.202 & 49 & $2.78 \pm 0.141$ & 0.116 \\
\hline
\end{tabular}

Data on number of embryos transferred were missing for 17 women (16 in the control group and one in the isolated group)

Table 6: Clinical pregnancies and the numbers of embryos transferred in women of different age classes in the second attempt

\begin{tabular}{|c|c|c|c|c|c|}
\hline \multirow{2}{*}{$\begin{array}{c}\text { Age-class } \\
\text { (years) }\end{array}$} & \multirow[t]{2}{*}{ Group } & \multicolumn{2}{|c|}{ Age } & \multicolumn{2}{|c|}{ No. of embryos transferred } \\
\hline & & $N$ & $\begin{array}{c}\text { Number (\%) of } \\
\text { successful clinical } \\
\text { pregnancies }\end{array}$ & $N$ & Mean \pm SEM \\
\hline \multirow[t]{2}{*}{$\leq 29$} & Control & 37 & $14(37.84)$ & 37 & $3.05 \pm 0.102$ \\
\hline & Isolated & 21 & $13(61.90)$ & 21 & $3.10 \pm 0.153$ \\
\hline \multirow[t]{2}{*}{$30-32$} & Control & 65 & $25(38.46)$ & 61 & $2.95 \pm 0.111$ \\
\hline & Isolated & 24 & $11(45.83)$ & 24 & $3.08 \pm 0.169$ \\
\hline \multirow[t]{2}{*}{$35-40$} & Control & 84 & $25(29.76)$ & 80 & $2.96 \pm 0.078$ \\
\hline & Isolated & 34 & $14(41.18)$ & 34 & $3.15 \pm 0.120$ \\
\hline \multirow[t]{2}{*}{$>40$} & Control & 28 & $5(17.86)$ & 27 & $3.00 \pm 0.160$ \\
\hline & Isolated & 5 & $3(60.00)$ & 5 & $3.00 \pm 0.447$ \\
\hline \multirow[t]{2}{*}{ Total } & Control & 214 & $69(32.24)$ & 205 & $2.98 \pm 0.053$ \\
\hline & Isolated & 84 & $41(52.38)$ & 84 & $3.11 \pm 0.081$ \\
\hline
\end{tabular}

Data on number of embryos transferred were missing for nine women in the control group 
in the same dormitory room get synchronized (Whitten effect $)^{12}$-it would appear that the increase in the percentage of clinical pregnancy in the isolated group may be on account of prevention of the women from receiving smell signals of men other than their respective husbands. This implies that there may be an olfactory block to pregnancy in humans. As the isolation of women that led to more than $50 \%$ increase in the clinical pregnancy rate was done for 3 days which is the period required for implantation of the transferred embryo(s), it would seem that if there is an olfactory block to clinical pregnancy, it is likely to operate at the level of implantation.

If the above hypothesis is correct, it would imply that the chances of establishment of clinical pregnancy in a normal fertile woman, when the intercourse takes place at the right time, as in a woman following IVF/ICSI and embryo transfer, may depend, besides the known factors, such as age (and the number of embryos transferred in the case of IVF/ICSI), on two hitherto unrecognised factors as follows:

a. Olfactory compatibility of the woman with the male partner which may be determined genetically, and

b. The extent to which the woman is protected from the smell of all other men [except, probably, the identical twin of the male partner, remembering that a dog cannot distinguish between identical twins (Colin Blakemore, personal communication, demonstrated on BBC television during Episode 2 (The Sound of Silence) of the 1982 Royal Institution Christmas Lectures (Common Sense), December 1982] during the period required for implantation, i.e. 5 to 6 days after intercourse, or 3 days after embryo transfer following IVF/ICSI.

The above possibility of a specific physiological response to defined olfactory stimulus is supported by the following observations:

1. Women seem to intuitively prefer men who have a different MHC (major histocompatibility complex; HLA in humans) make-up in comparison to their own. ${ }^{19,20}$ The MHCs seem to be important determinants of individual-specific smell signals in animals. ${ }^{20}$

2. The success rates following use of assisted reproductive technologies, such as IVF or ICSI, seem to be partially determined genetically (like individual-specific olfactory signals); there are thus differences between Caucasian and African-American patients in this regard in an equal-access-to-care setting. ${ }^{21}$

3. In preliminary experiments, one of us (PMB with $S$ Dube, Annual Reports of Centre for Cellular and Molecular Biology, Hyderabad, for 1982-83, 1983-84 and 1985-86) had shown that, in mice, pregnancy as measured by litter size, was substantially blocked when, after mating, a mouse of a $\mathrm{H} 2$ (the MHC in mice) make-up that was different from that of the stud mouse but of which the rest of the immunological background was the same as of the latter, was put in the cage of the female. No such pregnancy block occurred when the nonstud male had the same $\mathrm{H} 2$ locus as the stud male, but an immunological background different from that of the stud male (the animals for this study were obtained from Dr WH Fridman of Institute Curie, Paris). MHC recognition in mice and in rats is known to be olfactionmediated, and mice can detect odour differences between strains that differ only in respect of their MHC. ${ }^{18}$

4. Olfactory inputs to hypothalamic neurons have been reported to control reproduction and fertility. ${ }^{22}$

In the light of the above observations, it would appear that the chances of establishment of pregnancy in normal cycles may increase substantially if the woman, after intercourse, is kept away from all men except the partner for 6 days that are required for implantation. Table 5 shows that the p-value of the difference between control and isolated women in regard to successful establishment of pregnancy, progressively decreased with age, from $<0.0006$ for women $\leq 29$ years to 0.070 for women between 36 and 40 and to 0.102 for women above 40 . It is possible that some kind of olfactory conditioning may be taking place as the woman grows older, reducing the effect of isolation. However, the existence of an olfactory block to implantation in humans (suggested by our study) must be considered, as of now, only an attractive possibility.

One important step in understanding is the mechanism of the possible olfactory block to clinical pregnancy described here may be to study the relationship between establishment of clinical pregnancy on the one hand, and the HLA make-up of the mating couple in normal cycles, and of the oocyte and sperm donors (including husband and wife as in the present study) in IVF/ICSI cycles, on the other.

\section{ACKNOWLEDGMENT}

We thank Colin Blakemore for providing details of his demonstration on $\mathrm{BBC}$ television.

\section{REFERENCES}

1. Andersen AN, Gianarol L, Nygren KG. Assisted reproductive technology in Europe 2000. Results generated from European registers by Eshre. Hum Reprod 2004;19:490-503.

2. Witsenburg C, Dieben S, Van der Westerlaken L, Verburg H, Naaktgeboren N. Cumulative live birth rates in cohorts of patients treated with in vitro fertilization or intracytoplasmic sperm injection. Fertil Steril 2005;84:99-107.

3. Malizia BA, Hacker MR, Penzias AS. Cumulative live-birth rates after in vitro fertilization. New Engl J Med 2009;360: 236-43. 
4. Remohi J, Gartner B, Gallardo E, Yalil S, Simon C, Pellicer A. Pregnancy and birth rates after oocyte donation. Fertil Steril 1997;67:717-23.

5. Macklon NS, Geraedts JP, Fauser BCJM. Conception to ongoing pregnancy: The black box of early pregnancy loss. Hum Reprod Update 2002;8:333-43.

6. Kovalevsky G, Patrizio P. High rates of embryo wastage with use of assisted reproductive technology: A look at the trends between 1995 and 2001 in the United States. Fertil Steril 2005;84:325-30.

7. Bruce HM. An exteroceptive block to pregnancy in mouse. Nature 1959;184:105

8. Bruce HM. Absence of pregnancy-block in mice when stud and test males belong to an inbred strain. J Reprod Fertil 1968;17: 407-08.

9. Parkes AS, Bruce HM. Olfactory stimuli in mammalian reproduction. Science 1961;134:1049-54.

10. Chipman RK, Fox KA. Oestrous synchronization and pregnancy blocking in wild house mice (Mus musculus). J Reprod Fertil 1966;12:233-36.

11. Bowers JM, Alexander BK. Mice: Individual recognition by olfactory cues. Science 1969;158:1208-10.

12. Emes RD, Betson SA, Ponting CP, Goodstadt L. Evolution and comparative genomics of odorant- and pheromone-associated genes in rodents. Genome Res 2004;14:591-602.

13. Salumets A, Hyden-Granskog C, Makinen S, Snikkari AM, Tittinen A, Tuuri T. Early cleavage predicts the viability of human embryos in elective single embryo transfer procedure. Hum Reprod 2003;18:821-25.

14. Diedrich K, Diedrich C, Santos E, Zoll C, Al-Hasani S, Reissmann T, et al. Suppression of the endogenous luteinizing hormone surge by the gonadotrophin-releasing hormone antagonist cetrorelix during ovarian stimulation. Hum Reprod 1994;9:788-91.

15. Kolibianakis EM, Collins J, Tarlatzis BC, Devroey P, Diedrich K, Griesinger G. Among patients treated for IVF with gonadotrophins and $\mathrm{GnRH}$ analogues, is the probability of live birth dependent on the type of analogue used? A systematic review and meta-analysis. Hum Reprod Update 2006;12: $651-71$.

16. Gindes L, Yoeli R, Orvieto R, Shelef M, Ben-Rafael Z, Bar-Hara I. Pregnancy rate fluctuations during routine work in an assisted reproduction technology unit. Hum Reprod 2003;18: 2485-88.

17. Bhargava PM, Chakrabarti C. The fantastic power of smell signals that permeate our environment. Do human pheromones exist? Sci Reporter 1994;31(11):24-27.
18. Wyatt TD. Fifty years of pheromones. Nature 2009;457: 262-63.

19. Ober C. Studies of HLA, fertility and mate choice in a human isolate. Hum Reprod Update 1999;5:103-07.

20. Roberts SC, Gosling LM, Carter V, Petrie M. MHC-correlated odour preferences in humans and the use of oral contraceptives. Proc Roy Soc B 2008;275:2715-22.

21. Feinberg EC, Larsen FW, Catherino WH, Zhang J, Armstrong AY. Comparison of assisted reproductive technology utilization and outcomes between Caucasian and African American patients in an equal-access-to-care setting. Fertil Steril 2006;85:888-94.

22. Yoon H, Enquist LW, Dulac C. Olfactory inputs to hypothalamic neurons controlling reproduction and fertility. Cell 2005;123: $669-82$.

\section{ABOUT THE AUTHORS}

\section{Kamini A Rao}

Medical Director, Bangalore Assisted Conception Centre Private Limited, Bengaluru, Karnataka, India

\section{Muthugadhahalli S Srinivas}

Embryologist, Bangalore Assisted Conception Centre Private Limited Bengaluru, Karnataka, India

\section{Anu Kottur}

Consultant, Bangalore Assisted Conception Centre Private Limited Bengaluru, Karnataka, India

\section{Partha P Majumdar}

Director, National Institute of Biomedical Genomics, Kalyani West Bengal, India

\section{Pushpa M Bhargava}

Scientist, Anveshna, Andhra Pradesh, India

\section{CORRESPONDING AUTHOR}

Pushpa M Bhargava, Anveshna, 2-16-137/1 Road No. 3, Prashanthi Nagar, Uppal, Hyderabad-500039, Andhra Pradesh, India Phone: +91-40-27200982; +91-40-27200954, Fax: +91-4027200868 e-mail: bhargava.pm@gmail.com,pmb1928@yahoo.co.in 